\title{
From Space to School - Earth and Moon Observation in Immersion and Experiments
}

\author{
Christina Nadolsky, Arne Dröge-Rothaar, Johanna \\ Hemp, Lisa Keune, Claudia Lindner, Robin \\ Schönstein, Johannes Schultz, Carsten Jürgens, \\ Andreas Rienow \\ Department of Geography \\ Ruhr-University Bochum \\ Bochum, Germany \\ Christina.Nadolsky@rub.de
}

\author{
Judith Holländer, Susanne Hüttemeister \\ Zeiss Planetarium Bochum \\ Bochum, Germany
}

\author{
Alexander Küpper, Cristal Schult \\ Institute of Physics Education \\ University of Cologne \\ Cologne, Germany
}

\author{
Klaus Trimborn \\ zdi.NRW \\ Bochum, Germany
}

\section{INTRODUCTION}

education in Germany, the European Space Education Resource Office (ESERO) Germany was founded in May 2018. It was implemented by a consortium of ten institutions led by the Geomatics Research Group at the Department of Geography at the Ruhr-University Bochum, working in close collaboration with ESA Education (funding institution) and the German Aerospace Centre (DLR). Institutes of the University of Bonn, Cologne and of the Ruhr-University Bochum as well as the Planetarium, the Observatory Bochum and the network "Zukunft durch Innovation" are part of the consortium. During the so-called "Phase Study 0" the German educational system was analysed and a strategy to support STEM education in Germany was worked out. In comparison to other European countries, the educational system in Germany is structured by the states and not by the federal government. Thus, each of the $\mathbf{1 6}$ states decides on how to structure their educational system, which leads to multiple differences and a sum of nearly 450 different curricula in the STEM subjects. A strategy was needed to reach teachers and pupils in all federal states equally and motivate pupils for STEM subject. Therefore, a quantitative curriculum analysis was conducted by mapping the state curricula across the primary and secondary school education levels. As a result, ESERO Germany will focus on the competence orientation of STEM subjects and on the topics of the STEM curricula combined with applied space science. This is shown in our examples, three teaching units as part of ESA's Moon Camp Challenge and our designed Massive Open Online Courses (MOOC's) about Earth. These short videos combine geographic analysis and physical background information at the same time. Also, we present our Augmented Reality Application "From the Earth to the Moon and Back". The paper finishes with a short outlook on upcoming teacher trainings, competitions and classroom resources.

Keywords - education, earth observation, moon, classroom resources

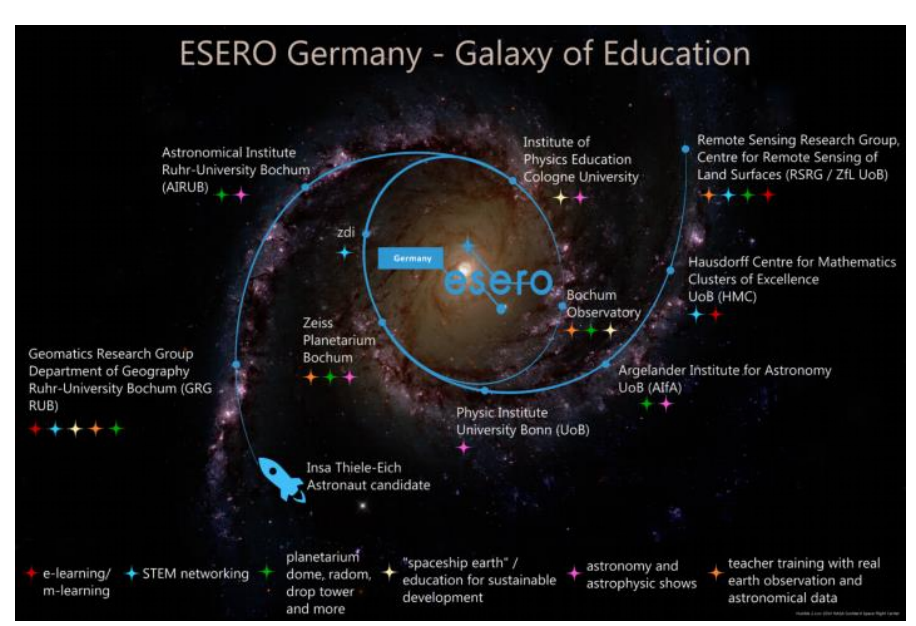

Fig. 1. The Galaxy of Education showing the ESERO Germany consortium and

their different tasks.

The European Space Education Resource Office (ESERO) Germany was funded in May 2018 in close collaboration with the European Space Agency (ESA) and the German Aerospace Center (DLR). The Geomatics Research Group at the Department of Geography of the Ruhr-University Bochum (RUB) leads the consortium of ten institutions. Furthermore, the consortium consists of the Zeiss Planetarium Bochum, the Chair of Astronomy at RUB, Bochum Observatory, the University of Bonn with the Remote Sensing Research Group at the Department of Geography, the Hausdorff Center for Mathematics, the Physics Institute, and the Argelander-Institute of Astronomy as well as the Institute of Physics Education at the University of Cologne and the well-known network 
"zdi.NRW - Zukunft durch Innovation" ("Shaping the future through innovation") (Fig. 1). The goal of ESERO Germany is to support the German STEM education by using the fascination of space to motivate and encourage both students and teachers. Therefore, classroom resources, teacher trainings and events are implemented regarding topics of applied space science such as earth observation, astronomy, navigation, communication, and exploration.

The paper presents the results of the so-called "Phase 0 Study" where the core curricula of STEM subjects were analysed, experts on education interviewed, and space professionals approached. A thorough mapping of the state curricula across the primary and secondary school education levels in Germany has been conducted, needs and potential areas of priority intervention were identified, and the role of space-related resources and activities in meeting these needs were assessed. Hence, it was possible to make recommendations for classroom resources and activities.

Our designed Massive Open Online Courses (MOOCs) about Earth Observation are an example of a classroom resource that can be used in different subjects and contexts and is therefore usable in the heterogeneous curricula. Additionally, resources for ESA's Moon Camp Challenge and Augmented Reality Apps dealing with the gravitation of the Earth-Moon system are depicted.

\section{THE GERMAN EDUCATIONAL SYSTEM}

In the school year 2017/2018, the German school educational landscape was shaped by $8,346,707$ pupils taught by 679,478 teachers at 37,121 schools in 16 federal states [1]. The German educational system is not structured by the federal government, but by the states. Thus, each state government can decide on how to structure their educational system [3]. This results in multiple differences between the federal states. This chapter gives an overview of the educational system focusing on the primary and secondary education (Fig. 2).

\section{A. Primary Education}

With the start of compulsory schooling the child enters primary education, meaning the time spent at primary school, which amounts to either four (e.g. North Rhine-Westphalia) or six (e.g. Berlin) years [3]. The main subjects are German, mathematics and general science ("Sachunterricht"). In addition, subjects such as a foreign language e.g. English, arts and physical education are taught. At the end of the primary education, a recommendation for a specific type of school is given [3]. It is based on former grades and will influence the following educational career .

\section{B. Secondary Education}

Primary education is followed by the lower secondary education, which is divided into different types of schools or holds different educational programmes [3]. The Hauptschule, Realschule and Gymnasium each aim for a specific type of school-leaving certificate (secondary modern school qualification, general certificate of secondary education, or Abitur, which is the equivalent to the British A level), that is usually gained after nine, ten, or twelve years, respectively. At

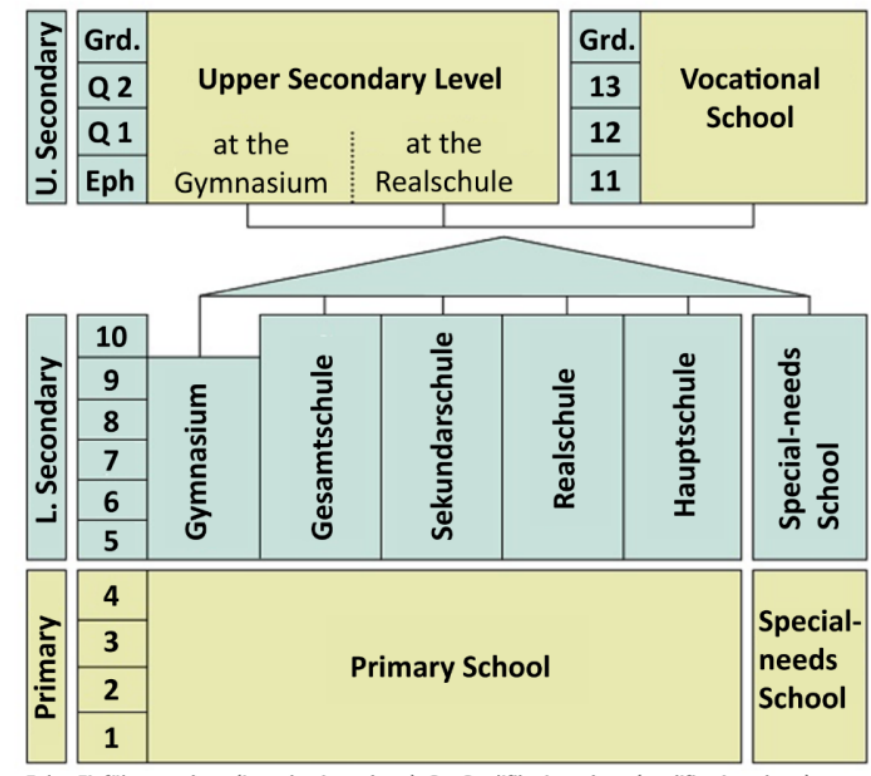

Eph = Einführungsphase (introductiory phase); Q = Qualifikationsphase (qualification phase)

Fig. 2. Overview of the German educational system [2]. Eph = "Einführungsphase" (introdutory phase); Q = "Qualifikationsphase" (qualification phase). The German school system is divided into primary (1$4^{\text {th }} / 6^{\text {th }}$ grade $)$, lower secondary $\left(5^{\text {th }} / 7^{\text {th }}-9^{\text {th }} / 10^{\text {th }}\right.$ grade $)$ and the upper secondary education $\left(10^{\text {th }} / 11^{\text {th }}-12^{\text {th }} / 13^{\text {th }}\right.$ grade $)$. It is possible to enter the upper secondary Education after the $9^{\text {th }}$ grade at the Gymnasium ("G8") or $10^{\text {th }}$ grade ("G9"). The major school types are: Grundschule (primary school), Gymnasium (grammar school), Gesamtschule (comprehensive school), Hauptschule, Realschule and Sekundarschule as secondary school and special-needs school.

Gesamtschulen, students do not follow one specific educational career from the start but rather participate in classes with different levels of difficulty. The general education schoolleaving certificate can be obtained at all secondary schools. This certificate qualifies the graduate to enter the upper secondary level. Gymnasium, Realschulen and full-time vocational schools and dual vocational trainings are all part of the upper secondary education [3]. The choice of the educational institution depends on the former school-leaving certificate.

This education level includes the following STEM-subjects: mathematics, computer science, biology, chemistry, physics, technology, and geography. In some curricula the subjects of biology, chemistry, and physics are treated as general science in the lower secondary level. The amount of curricula for these seven subjects in 16 federal states and the four different school types is approximately 448 - excluding primary schools and upper secondary classes!

\section{METHODOLOGY OF THE QUANTITATIVE CURRICULUM ANALYSIS}

The German educational system is complex and the topics and requirements for didactic material is different in each federal state. Hence, a well-conceived strategy was needed to handle the broad spectra of STEM curricula in Germany. Therefore, we had a close look at the national educational standards in order to detect congruities and similarities between 
the STEM subjects across the state borders. The analysis of secondary (lower and upper) education curricula was conducted for the STEM subjects of mathematics, computer science, biology, chemistry, physics, technology, geography and general science. Exemplary, the curricula of the Gymnasium, Gesamtschule, Realschule and Hauptschule were examined. For the primary education, the subjects general studies and mathematics were analysed. Not only contents, but also contexts were noted.

In addition, qualitative expert interviews were conducted, to get a deeper insight into the possibilities of implementing space-related topics, astronomy or astrophysics in schools. Our current and future activities are based on this curriculum analysis, the expert interviews and consultation of space education expert from the European Space Agency (ESA) and the German Aerospace Center (DLR). All results are combined in the so-called "Phase 0 Study".

\section{RESULTS}

\section{A. Educational Standards for STEM subjects and competence orientation}

To standardize the competencies of pupils upon the completion of primary education ( $4^{\text {th }}$ grade), lower secondary education $\left(10^{\text {th }}\right.$ grade) and the general higher education qualification entrance ("Abitur") national educational standards for the mathematics, physics, chemistry, biology and languages were developed in Germany. In addition to these educational standards [4, 5, 6, 7], several associations propose further standards in the fields of informatics [8], technology [9] and geography [10] to complete the STEM subjects.

Tab. 1 presents the competencies for the most relevant STEM subjects in Germany. The colums represent the subjects and the lines describe the different competencies for this subject. Merged lines show competencies that are needed in more than one subject. The subject of technology has a special position as it can act as a link between all subjects. The competencies in the field of technology include the usage, the comprehension and the construction of technical components in diverse fields of actions like transport and traffic or information and communication. In Germany, technical subjects can be found under a variety of names (e.g. "work, economy, technology" or "work science"). Since the integration into the curriculum of neither technology nor informatics is mandatory, the conveyance of technical competencies and computer skills is rather difficult. Thanks to the diverse applicability of technical devices, an integration of these competencies into lessons is certainly possible.

The competence of communication is seen to be taught in all subjects. Pupils ought to communicate subject-related contents correctly and exchange information with one another. In the case of maths, this means that the facts are considered mathematically.

Another competence in the subjects of biology, chemistry and physics is the acquisition of knowledge. This particularly includes the planning, execution and evaluation of experiments. Quite similar is the competence apply methods in the subject of geography. The pupils should develop the ability to gain and
TABLE I. THE COMPETENCIES FOR THE MAIN STEM SUBJECTS OF MATHEMATICS, INFORMATICS, PHYSICS, BIOLOGY, CHEMISTRY, AND GEOGRAPHY AND TECHNOLOGY (LOWEST COLUMN). THE REFERENCES FOR THE SUBJECTS ARE MATHEMATICS [4], INFORMATICS [8], PHYSICS [5], BIOLOGY [7], CHEMISTRY [6], GEOGRAPHY [10], AND TECHNOLOGY [9]. TECHNOLOGY TAKES OVER A SPECIAL PART AS IT CAN BE COMBINED WITH ALL OTHER SUBJECTS. ALL COMPETENCIES ARE INTERESTING TO ADDRESS IN THE CLASSROOM RESOURCES.

\begin{tabular}{|c|c|c|c|c|c|}
\hline Math & Informatics & Physics & Biology & Chemistry & Geography \\
\hline \multicolumn{6}{|c|}{ communication } \\
\hline \multirow{3}{*}{$\begin{array}{l}\text { argue } \\
\text { mathe- } \\
\text { mati- } \\
\text { cally }\end{array}$} & \multicolumn{5}{|c|}{ reason/evaluate } \\
\hline & \multicolumn{5}{|l|}{ expertise } \\
\hline & & $\begin{array}{l}\text { acquisiti } \\
\text { (experim }\end{array}$ & nt) & knowledge & $\begin{array}{l}\text { apply } \\
\text { methods }\end{array}$ \\
\hline \multicolumn{2}{|c|}{$\begin{array}{l}\text { use and interpret } \\
\text { visualizations }\end{array}$} & & & & \\
\hline \multicolumn{2}{|c|}{ modelling } & & & & action \\
\hline $\begin{array}{l}\text { deal } \\
\text { with } \\
\text { formal } \\
\text { and } \\
\text { sym- } \\
\text { bolic } \\
\text { ele- } \\
\text { ments } \\
\text { of } \\
\text { maths }\end{array}$ & $\begin{array}{l}\text { structure } \\
\text { and connect }\end{array}$ & & & & $\begin{array}{l}\text { spatial } \\
\text { orientation }\end{array}$ \\
\hline \multicolumn{2}{|c|}{ Technology } & \multicolumn{2}{|l|}{ utilize } & \multicolumn{2}{|c|}{ construct/produce } \\
\hline
\end{tabular}

evaluate relevant information from different media. Another component is the spatial orientation and the usage of maps. Based on identified problems, the pupils should develop strategies of action that suit the natural and social environment. Especially the use of satellite images can increase methodological skills. This does not only apply to the subject of geography, but also chemistry and biology.

The subjects of math and informatics comprise similar competencies. The use and interpretation of visualizations is part of both subjects. The pupils ought to develop, understand and use models. In the subject of informatics, the pupils learn how to structure and pointedly connect coherences.

All competencies are interesting to address in the classroom resources.

\section{B. Recommendations for didactics material}

There is a general consent that interdisciplinary and subject specific learning is supposed to arouse and deepen the curiosity, interests and inclinations of the students. It is very noticeable that the field of natural phenomena occurs in almost all curricula. The offering of space-related topics adds value by fascinating pupils early on and by providing easily applicable materials for teachers. The competency model for the subjects 
of math, physics, informatics, technology, biology, chemistry and geography allows the integration of space-related topics and content into tuition regardless of the federal state. As the materials focus on the competencies to be taught, it is possible to integrate them into lessons in many federal states and school types. The thematic relation to space serves as a means to an end, whereby the applicability increases.

It is necessary to create and adapt existing educational resources based on a didactic concept addressing independent working, discovery-based learning and propaedeutic learning $[11,12]$. The materials should be, if possible, in conformity with the general curricula. To achieve this, the material should be structured in a modular way and flexible at use regarding the student's competencies, grade and school type. This can be supported by having the possibility to edit the material and customize it for the individual needs of the learning group. The tasks should be short enough to split the whole material into smaller packages, which can be used flexible in the different length of the lessons. Each of the material should provide a didactic note with tips and recommendation for a use in the classroom.

This holds true for primary as well as secondary materials. The main difference will be a stronger emphasis on instructions in the primary education resources.

To motivate students for STEM subjects, a focus on topics of applied space science like earth observation, space travel, (exo-) planetary research, astronomy/astrophysics, GNSSNavigation, satellite communication, space technology in everyday life is recommended.

Possible topics for mathematics are for example the analysis and classification of geometric objects and statistical analysis. In geography the possibilities are huge especially in combination with Earth Observation and Remote Sensing. There are also several possibilities in chemistry: energy storage systems or plastics.

\section{EXAMPLES}

Since the ESERO Germany opening ceremony in May 2018 a lot of different classroom resources were produced. In the following, some examples are given. All material can be found on www.esero.de.

\section{A. Experimental Learning}

An example for modular classroom resources regarding space technology and science are developed by ESA Education and part of the Teach with Space material. Five worksheets [13, 14, $15,16,17]$ have been translated and adapted into German to support the Moon Camp Challenge. The tasks of this challenge is to design a $3 \mathrm{D}$ model of a moon camp by using 3D-modelling software. The translated material reaches from planning and designing a lunar lander [15] to building a shelter [16] and bionic hands [14]. By filtering "lunar ice cores" (dirty ice cubes) [17] and learning about edible plants in space [13] the students are discussing the dangers and possibilities of the Moon. In addition, the material provides background information and several interesting links for teachers. The resources can be used interdisciplinary and can be split up between the lessons or even parts can be done as a homework.
Because of that, the resources can be used flexible and individually in the German classroom. The material is suitable for students from 6 to 10 years [13] 8 to 12 years $[14,16,17]$ and 14 to 16 years [15] which suits both primary and lower secondary education in Germany. Also, the material can be used independently from the competition when referring to the Moon and the $50^{\text {th }}$ anniversary of the Moon Landing.

\section{B. MiniMOOCs about Earth Observation}

Other classroom resources are Mini Massive Open Online Courses (MiniMOOC) about Earth Observation and Remote Sensing (RS). The material was produced during the project "Fernerkundung in Schulen", which is also located at the Departement of Geography of the Ruhr-University Bochum. This material consists of short videos (4 to 6 minutes long) about different subtopics of Earth Observation and its physical background. The videos can be used as a stand-alone or combined and interdisciplinary to introduce a topic or technique in the lessons. Currently six MOOC's are available on the ESERO Germany website. When using them as a series, the first MiniMOOC ("Images from Space") is an introduction to Remote Sensing and RS satellites e.g. Sentinel 2 or Meteosat. The following videos describe the electromagnetic spectrum ("The Electromagnetic Spectrum -part 1" and "The Electromagnetic Spectrum - part 2") in two parts. After that, the students get an insight in the usage of infrared imagery ("The world in infrared"). "The spectral resolution" and the "spatial resolution" and the different satellites are discussed in the last recently published MiniMOOCs. All videos can be downloaded for free and are also available with English subtitles on www.esero.de/post/413.

\section{Augmented Reality Application: From Earth to Moon}

The project "Columbus Eye - Live-Bilder von der ISS im Schulunterricht" and its successor "KEPLER ISS" are based at the Department of Geography of the Ruhr-University Bochum and create interactive and digital learning material. The latest Augmented Reality Application, "From the Earth to the Moon and Back" deals with the gravitational system of the Earth and the Moon. The students can use their phone to turn it into the Moon and changing the distance to the Earth on their worksheets. The real distance is shown on the screen. Additionally, the students can investigate the change of the maximum and minimum tides level in the German Bight on a true-colour Sentinel-2 image. This classroom resource can be used in the $11^{\text {th }}$ grade (16 to 17 years) physics class. The material consists of the worksheets, the tasks' solution and some background information. By using the Augmented Reality App the comprehension and motivation for STEM subjects of the students is increasing [18]. The lack of IT infras tructure in schools can be covered by using the students' smartphone. This material is available for free in German and in English on www.esero.de/post/160.

\section{CONCLUSION AND FUTURE WORK}

In the German educational system the curriculum is given by the federal states. In combination with the different school types, the number of curricula for the STEM subject is high. To 
produce classroom resources that can be used in all federal states the European Space Education Resource Office (ESERO) Germany conducted a curriculum analysis by mapping the core curricula and identifying the potential areas and didactic focus. Competence orientation and a thematic focus on applied space science topics is key to produce flexible and usable material. The material should be modular to use it in different grades and difficulties. By addressing independent working, inquiry-based learning and propaedeutic learning in the classroom resources the pupils' competencies will be strengthened and their motivation for STEM subjects increased [11, 12]. Besides having material in conformity with the curricula, it should be structured in a modular way, editable and flexible at use in the classroom.

Different teaching materials have been produced by ESERO Germany since the opening in May 2018. These materials are available for free on the website and support Earth Observation activities and competitions by the European Space Agency.

In the future, a focus will lie on Space Exploration and Earth Observation. Many more resources by ESA Education will be translated and adapted into German. Also, teaching material supporting the exhibition INNOspaceExpo is planned. The development of material is accompanied by teacher trainings focussing on gaining basic knowledge and exploring the variety of material.

\section{ACKNOWLEDGMENT}

The European Space Education Resource Office is funded by the European Space Agency and supported by the German Aerospace Center (DLR). FIS, Columbus Eye and KEPLER ISS are supported by the German Aerospace Center (DLR) with funds of the Federal Ministry for Economic Affairs and Energy [grant numbers 50EE1703, 50JR1307 and 50JR1701] based on a resolution of the German Bundestag.

\section{REFERENCES}

[1] Statistisches Bundesamt
https://www.destatis.de/DE/ZahlenFakten/GesellschaftStaat/BildungFor schungKultur/Schulen/Schulen.html [14.08.2018].

[2] Ministerium für Schule und Bildung des Landes Nordrhein-Westfalen, „Schulformen. Das Schulsystem in NRW,“
https://www.schulministerium.nrw.de/docs/Schulsystem/Schulformen/in dex.html [14.08.2018].

[3] B. Edelstein, "Das Bildungssystem in Deutschland. Bildungseinrichtungen, Übergänge und Abschlüsse, “ Bundeszentrale für politische Bildung, 2013.

[4] Sekretariat der Ständigen Konferenz der Kultusminister der Länder in der Bundesrepublik Deutschland, „Bildungsstandards im Fach Mathematik für den Mittleren Schulabschluss, "Wolters Kluwer Deutschland GmbH, 2004.

[5] Sekretariat der Ständigen Konferenz der Kultusminister der Länder in der Bundesrepublik Deutschland, „Bildungsstandards im Fach Physik für den Mittleren Schulabschluss, “Wolters Kluwer Deutschland GmbH, 2005.

[6] Sekretariat der Ständigen Konferenz der Kultusminister der Länder in der Bundesrepublik Deutschland, „Bildungsstandards im Fach Chemie für den Mittleren Schulabschluss," Wolters Kluwer Deutschland GmbH, 2005 .

[7] Sekretariat der Ständigen Konferenz der Kultusminister der Länder in der Bundesrepublik Deutschland,"Bildungsstandards im Fach Biologie für den Mittleren Schulabschluss," Wolters Kluwer Deutschland GmbH, 2005 .

[8] Gesellschaft für Informatik (GI) e.V., "Grundsätze und Standards für die Informatik in der Schule,“ LOG IN, 28. Jg, vol. 150/151, 2008.

[9] VDI Verein Deutscher Ingenieure e.V. „Bildungsstandard Technik für den Mittleren Schulabschluss,“ 2007. https://www.vdi.de/bildung/fuerden-mittleren-schulabschluss/ [26.08.2018].

[10] Deutsche Gesellschaft für Geographie, "Bildungsstandards im Fach Geographie für den Mittleren Schulabschluss mit Aufgabenbeispielen,“ Selbstverlag Deutsche Gesellschaft für Geographie, 2014.

[11] K. Voß, R. Goetzke, H. Hodam, and A. Rienow, "Remote Sensing, New Media and Scientific Literacy - A New Integrated Learning Portal for Schools Using Satellite Images," Learning with GI 2011 - Implementing Digital Earth in Education, Berlin, pp. 172-180.

[12] A. Ortwein et al., "Pushed Beyond the Pixel - Interdisciplinary Earth Observation Education from the ISS in Schools," Proceedings of the 67th International Astronautical Congress 2016 26-30 September in Guadalajara, Mexico, 1-6.

[13] European Space Agency, ,teach with space - astrofood | PR41,”European Space Agency, 2019.

[14] European Space Agency, ,teach with space - bionic hand | PR34," European Space Agency, 2018.

[15] European Space Agency, ,teach with space - landing on the moon | P37," European Space Agency, 2018.

[16] European Space Agency, „teach with space -moon shelter | PR37,” European Space Agency, 2018.

[17] European Space Agency, ,teach with space - water on the moon | PR33, European Space Agency, 2018.

[18] C. Lindner, A. Rienow, C. Jürgens, "Augmented Reality applications as digital experiments for education - An example in the Earth-Moon System," Acta Astronautica 161, 2019 